\title{
analisis Penaatan Pemrakarsa Kegiatan Bidang Kesehatan Di Kota Magelang Terhadap PENGElolaAn DAn PEMANTAUAN Lingkungan HiduP
}

\author{
Prathika Andini Goesty ${ }^{1}$, Adji Samekto², Dwi P Sasongko ${ }^{3}$ \\ ${ }^{1}$ Program Studi Magister Ilmu Lingkungan, Program Pascasarjana Universitas Diponegoro, Semarang \\ ${ }^{2}$ Fakultas Hukum Universitas Diponegoro \\ ${ }^{3}$ Fakultas Sains dan Matematika Universitas Diponegoro \\ Email : dini_phoedhink@yahoo.com
}

\begin{abstract}
ABSTRAK
Salah satu instrumen untuk mengelola dampak lingkungan adalah UKL-UPL, namun pemrakarsa belum sepenuhnya melakukan pengelolaan dan pemantauan lingkungan, tercermin dari data yang dimiliki Kantor Lingkungan Hidup Kota Magelang bahwa jumlah pelaporan rutin pemrakarsa sebesar 0\%. Penelitian ini bertujuan untuk menganalisis ketaatan serta kendala pemrakarsa dalam mengimplementasikan UKL-UPL serta pengawasan oleh Kantor Lingkungan Hidup Kota Magelang. Objek penelitian adalah 6 kegiatan di bidang kesehatan. Penelitian dilakukan menggunakan metode observasi dengan pendekatan analisis bersifat preskriptif berbasis data kualitatif. Hasil penelitian menunjukkan bahwa pemrakarsa belum taat, dikarenakan : 1) Belum menyadari bahwa lingkungan hidup adalah kepentingan publik yang tidak boleh dirusak, 2) SDM dan sarana kurang memadai, 3) Anggaran besar. Pengawasan yang dilakukan Kantor Lingkungan Hidup Kota Magelang belum berjalan sebagaimana diharapkan. Pengawasan dan koordinasi yang ada selama ini bersifat reaktif.
\end{abstract}

Kata kunci: UKL-UPL bidang kesehatan, analisis penaatan, pengelolaan dan pemantauan lingkungan

\begin{abstract}
Environmental Management and Monitoring Effort (UKL-UPL) is one of important instruments for maintaining environmental impact management. however, the effort has not been properly implemented in Magelang territory, according to data reported by the Municipal Office of Environmental Affairs of Magelang. It is disappointing that the local initiators did not give any routine report concerning the implementation progress. This study aimed to analyze degree of compliance and problems faced by the environmental initiators in implementing the UKL-UPL as well as monitoring by the Municipal Office of Environmental Affairs of Magelang. The study was obtained by an observation method using a prescriptive analytical approach based on qualitative data. Result of the study showed that the initiators' lacking degree of compliance had caused poor quality of the environmental management and monitoring. Problems that faced the initiators included 1) poor awareness of the importance of preserving and sustaining the environment for common good, 2) poor quality of human resource and facilities, and 3) lacking budget. The Municipal Office of Environmental Affairs of Magelang had not performed monitoring properly. Both monitoring and co-ordination were still reactionary whenever a problem arose.
\end{abstract}

Keywords: UKL-UPL based environmental health, analysis of compliance, management and monitoring

\section{Pendahuluan}

Menurut Undang-undang Nomor 32 Tahun 2009 Pasal 22 ayat (1) bahwa "setiap usaha dan/atau kegiatan yang berdampak penting terhadap lingkungan hidup wajib memiliki Amdal" dan Pasal 34 ayat (1) bahwa "setiap usaha dan/atau kegiatan yang tidak termasuk dalam kriteria wajib Amdal, wajib memiliki UKL-UPL". Dokumen lingkungan ini digunakan sebagai instrumen pencegahan pencemaran dan untuk meminimasi dampak yang dihasilkan dari usaha, maka setiap pemrakarsa yang usahanya menghasilkan dampak negatif ke lingkungan baik fisik maupun non fisik diwajibkan untuk membuat dokumen kelayakan lingkungan sebelum usaha tersebut berjalan.

Setelah mendapatkan rekomendasi UKL-UPL dan kegiatan berjalan maka pemrakarsa harus melakukan pelaporan secara periodik kepada instansi lingkungan hidup di wilayah administratifnya (Said, 2006). Menurut Sabaruddin (2007), instansi yang bertanggung jawab di bidang lingkungan hidup mempunyai kewenangan dalam pengendalian dampak lingkungan, pencemaran, dan kerusakan lingkungan serta pengawasan pelaksanaan UKL-UPL di daerahnya.

Peran yang efektif dari pemerintah diperlukan dalam dokumen lingkungan, agar dapat lebih meningkatkan 
kualitas dan integritas dokumen lingkungan (Ross, 2006). Koordinasi/hubungan dan mekanisme kerja antar pusat, provinsi, dan kabupaten/kota sangat diperlukan, sehingga terdapat kejelasan mandat, untuk menghindarkan terjadinya kerancuan dan tumpang tindihnya wewenang dan tanggung jawab di bidang pengelolaan sumberdaya alam dan lingkungan. Sosialisasi dan komunikasi menjadi kunci penting bagi implementasi pembangunan berwawasan lingkungan (Sarbi, 2006).

Kota Magelang merupakan kota jasa yang cukup strategis karena terletak di antara 2 kota besar yaitu Semarang dan Yogyakarta. Perekonomian Kota Magelang ditopang dari berbagai sektor, baik pariwisata, industri, perdagangan, kesehatan, maupun kegiatan usaha lainnya. Untuk mencegah terjadinya pencemaran lingkungan, usaha di berbagai sektor tersebut membuat dokumen lingkungan. Usaha di bidang kesehatan memiliki karakterisitik limbah yang lebih beragam dan perlu penanganan khusus jika dibandingkan dengan bidang usaha lainnya, hal ini terkait dengan aktivitas di dalamnya. Limbah yang dihasilkan ada limbah infeksius dan noninfeksius.

Seluruh kewajiban yang tercantum dalam UKL-UPL juga wajib dilaksanakan oleh penanggungjawab usaha dan/atau kegiatan dan dilaporkan secara berkala kepada instansi lingkungan hidup pusat, provinsi dan/atau kabupaten/kota sesuai dengan kewenangannya. Hal ini sesuai dengan apa yang tertuang di dalam Peraturan Menteri Negara Lingkungan Hidup Nomor 13 Tahun 2010 tentang Upaya Pengelolaan Lingkungan dan Upaya Pemantauan Lingkungan Hidup dan Surat Pernyataan Kesanggupan Pengelolaan dan Pemantauan Lingkungan Hidup.

Pada kenyataannya, tingkat ketaatan pemrakarsa untuk melaksanakan dokumen UKL-UPL di Kota Magelang juga masih sangat rendah, yaitu $0 \%$. Hal ini ditunjukkan oleh belum adanya pelaporan secara periodik mengenai pelaksanaan pengelolaan dan pemantauan lingkungan oleh pemrakarsa kepada Kantor Lingkungan Hidup Kota Magelang (Kantor Lingkungan Hidup Kota Magelang, 2012).

Berdasarkan hal tersebut diatas maka perlu dilakukan penelitian untuk mengetahui tingkat ketaatan pemrakarsa dan kendala-kendala apa saja yang dihadapi dalam mengimplementasikan dokumen UKLUPL serta menganalisis pengawasan pelaksanaan pengelolaan dan pemantauan lingkungan oleh Kantor Lingkungan Hidup Kota Magelang.

\section{Material Dan Metode Penelitian}

Objek penelitian adalah pemrakarsa usaha di bidang kesehatan yang memiliki dokumen UKL-UPL di Kota Magelang, yaitu : 1) RSIA Puri Agung, 2) RSB Amandha, 3) Laboratorium Klinik Prodia, 4) RS Harapan, 5) RS Lestari Raharja, 6) RSIA Gladiool.

Untuk menganalisis penaatan pemrakarsa digunakan kriteria penaatan yang diadopsi dan dimodifikasi dari kriteria Proper yang ada di dalam Peraturan Menteri Negara Lingkungan Hidup No. 5 Tahun 2011 tentang Program Penilaian Peringkat Kinerja Perusahaan Dalam Pengelolaan Lingkungan Hidup. Kriteria pelaksanaan pengelolaan dan pemantauan lingkungan terdiri dari :

1. Dokumen UKL-UPL : Kepemilikan, implementasi dan pelaporan

2. Pengendalian pencemaran air (air bersih dan air limbah) : baku mutu, pemantauan, pelaporan, perizinan, ketaatan terhadap ketentuan teknis

3. Pengendalian pencemaran udara (ambien) : baku mutu, pemantauan, pelaporan

4. Pengendalian gangguan : baku mutu kebisingan, pelaporan

5. Pengelolaan Limbah B3 : pendataan jenis dan volume limbah yang dihasilkan, pelaporan, jumlah limbah B3 yang dikelola, pengelolaan limbah B3 oleh pihak ketiga

Setiap kriteria dibagi atas 3 jenjang dan diberi skor 1 sampai 3, untuk skor 1 artinya tidak taat, skor 2 artinya belum taat, dan skor 3 artinya taat. Setelah itu skor untuk semua kriteria dijumlah dan didapat jumlah skor total. Tingkat ketaatan pemrakarsa berdasarkan skor total tersebut disajikan dalam Tabel 1.

Tabel 1. Tingkat Ketaatan

\begin{tabular}{cc}
\hline Skor & Tingkat Ketaatan \\
\hline $18-29$ & tidak taat \\
$30-41$ & belum taat \\
$42-54$ & taat \\
\hline
\end{tabular}

Untuk mengetahui kendala yang dihadapi pemrakarsa dan pengawasan dari Kantor Lingkungan Hidup Kota Magelang digunakan data primer dari wawancara mendalam dengan panduan daftar pertanyaan.

\section{Hasil Dan Pembahasan}

3.1 Tingkat Penaatan Pemrakarsa

Tingkat ketaatan pemrakarsa disajikan pada Tabel 2. 
Prathika Andini Goesty, Adji Samekto, Dwi P. Sasongko. 2012. Analisis Penaatan Pemrakarsa Kegiatan Bidang Kesehatan di Kota Magelang terhadap Pengelolaan dan Pemantauan Lingkungan Hidup. Jurnal Ilmu Lingkungan, Vol 10 (2):89-94. http://ejournal.undip.ac.id/index.php/ilmulingkungan

Tabel 2. Tingkat Penaatan Pemrakarsa

\begin{tabular}{|c|c|c|c|c|c|c|c|c|c|}
\hline & Kriteria & Sub kriteria & Skor & PA & RS A & Lab & RS H & RS LR & RSIA G \\
\hline Dokumen UKL-UPL & $\begin{array}{l}\text { Kepemilikan dan } \\
\text { implementasi }\end{array}$ & $\begin{array}{l}\text { Punya } \\
\text { Melaksanakan } \\
\text { Melaporkan } \\
\text { Punya } \\
\text { Tidak Melaksanakan } \\
\text { Tidak Melaporkan } \\
\text { Tidak Punya } \\
\end{array}$ & $\begin{array}{l}2 \\
1 \\
\end{array}$ & 2 & 2 & 2 & 2 & 2 & $\begin{array}{l}- \\
- \\
-\end{array}$ \\
\hline $\begin{array}{c}\text { Pengendalian } \\
\text { Pencemaran Air } \\
\text { (Air bersih) }\end{array}$ & Baku Mutu & $\begin{array}{l}\text { Semua parameter } \\
\text { memenuhi baku mutu } \\
\text { Ada Parameter yang } \\
\text { belum memenuhi baku } \\
\text { mutu } \\
\text { Semua parameter tidak } \\
\text { memenuhi baku mutu }\end{array}$ & 1 & 3 & 3 & 3 & 2 & 2 & - \\
\hline & Pemantauan & $\begin{array}{l}\text { Rutin melakukan } \\
\text { pemantauan } \\
\text { Melakukan pemantauan } \\
\text { tetapi tidak rutin } \\
\text { Tidak pernah } \\
\text { melakukan pemantauan }\end{array}$ & $\begin{array}{l}3 \\
2 \\
1\end{array}$ & 3 & 3 & 3 & 3 & 3 & $\begin{array}{l}- \\
- \\
-\end{array}$ \\
\hline & Pelaporan & $\begin{array}{l}\text { Rutin melakukan } \\
\text { pelaporan } \\
\text { Melakukan pelaporan } \\
\text { tetapi tidak rutin } \\
\text { Tidak pernah } \\
\text { melakukan pelaporan } \\
\end{array}$ & $\begin{array}{l}3 \\
2\end{array}$ & 1 & 1 & 1 & 1 & 1 & $\begin{array}{l}- \\
- \\
-\end{array}$ \\
\hline $\begin{array}{l}\text { Pengendalian } \\
\text { Pencemaran Air } \\
\text { (air limbah) }\end{array}$ & Baku Mutu & $\begin{array}{l}\text { Semua parameter } \\
\text { memenuhi baku mutu } \\
\text { Ada Parameter yang } \\
\text { belum memenuhi baku } \\
\text { mutu } \\
\text { Semua parameter tidak } \\
\text { memenuhi baku mutu }\end{array}$ & 2 & 1 & 1 & 1 & 1 & 1 & $\begin{array}{l}- \\
- \\
-\end{array}$ \\
\hline & Pemantauan & $\begin{array}{l}\text { Rutin melakukan } \\
\text { pemantauan } \\
\text { Melakukan pemantauan } \\
\text { tetapi tidak rutin } \\
\text { Tidak pernah } \\
\text { melakukan pemantauan }\end{array}$ & $\begin{array}{l}3 \\
2 \\
1\end{array}$ & 1 & 1 & 1 & 1 & 1 & $\begin{array}{l}- \\
- \\
-\end{array}$ \\
\hline & Pelaporan & $\begin{array}{l}\text { Rutin melakukan } \\
\text { pelaporan } \\
\text { Melakukan pelaporan } \\
\text { tetapi tidak rutin } \\
\text { Tidak pernah } \\
\text { melakukan pelaporan } \\
\end{array}$ & $\begin{array}{l}3 \\
2 \\
1\end{array}$ & 1 & 1 & 1 & 1 & 1 & $\begin{array}{l}- \\
- \\
-\end{array}$ \\
\hline & Perizinan & $\begin{array}{lr}\text { Memiliki } & \text { izin } \\
\text { pembuangan limbah } \\
\text { cair dan masih berlaku } \\
\text { Memiliki izin } \\
\text { pembuangan limbah } \\
\text { cair tetapi sudah habis } \\
\text { masa berlakunya } \\
\text { Tidak memiliki izin } \\
\text { pembuangan limbah } \\
\text { cair }\end{array}$ & 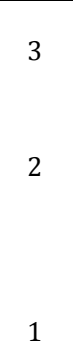 & 1 & 1 & 1 & 1 & 1 & - \\
\hline & $\begin{array}{c}\text { Ketaatan } \\
\text { terhadap } \\
\text { ketentuan teknis }\end{array}$ & $\begin{array}{l}\text { Mematuhi semua aturan } \\
\text { teknis } \\
\text { Belum mematuhi semua } \\
\text { aturan teknis } \\
\text { Tidak mematuhi semua } \\
\text { aturan teknis }\end{array}$ & $\begin{array}{l}3 \\
2 \\
1\end{array}$ & 2 & 2 & 2 & 2 & 2 & $\begin{array}{l}- \\
- \\
-\end{array}$ \\
\hline $\begin{array}{c}\text { Pengendalian } \\
\text { Pencemaran udara } \\
\text { (ambien) }\end{array}$ & Pemantauan & $\begin{array}{l}\text { Rutin melakukan } \\
\text { pemantauan } \\
\text { Melakukan pemantauan } \\
\text { tetapi tidak rutin } \\
\text { Tidak pernah } \\
\text { melakukan pemantauan }\end{array}$ & $\begin{array}{l}3 \\
2\end{array}$ & 1 & 1 & 2 & 1 & 1 & $\begin{array}{l}- \\
- \\
-\end{array}$ \\
\hline
\end{tabular}




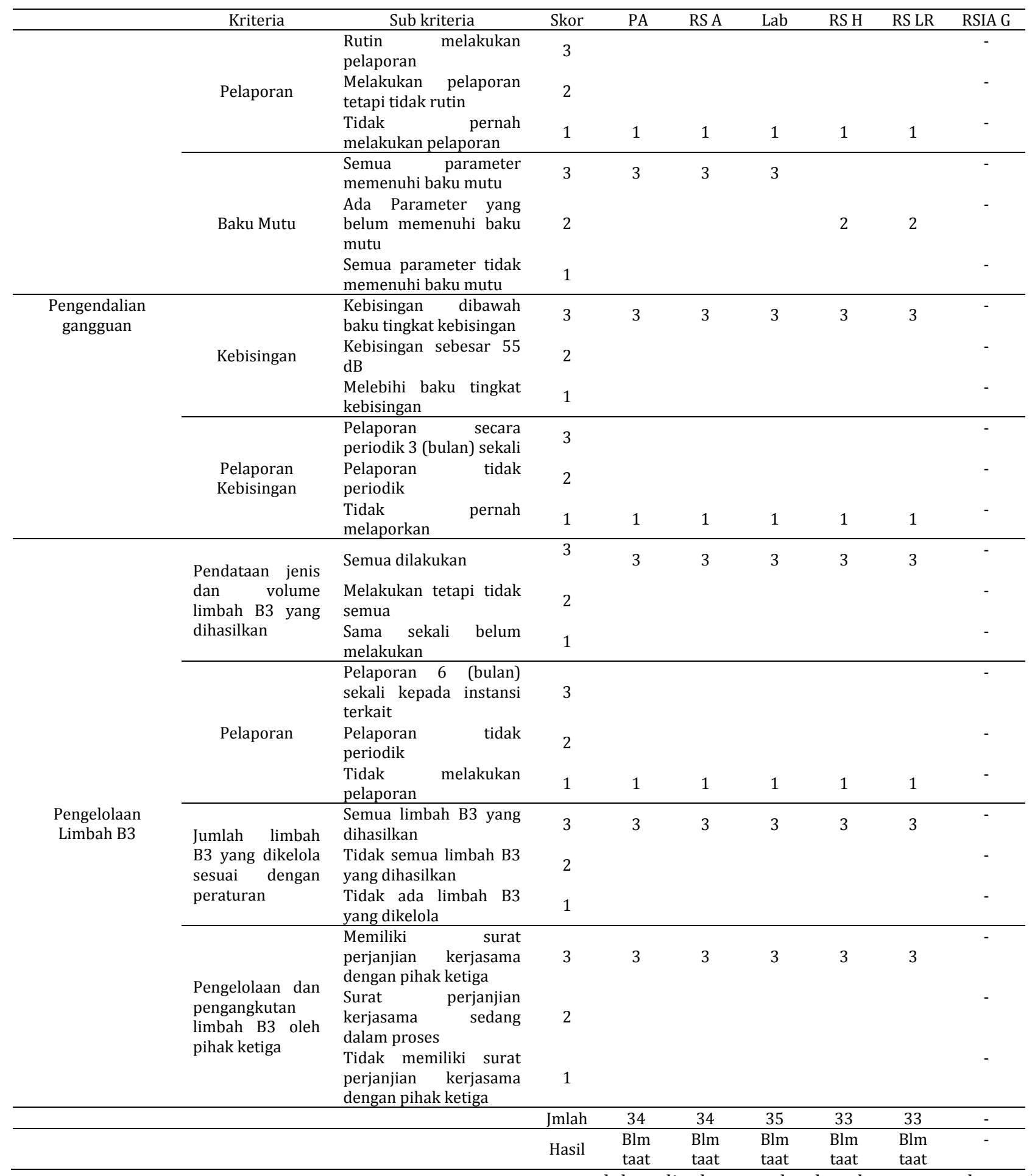

RSIA Gladiool tidak ada data untuk semua kriteria. Hal ini dikarenakan adanya ketidakterbukaan informasi rumah sakit tersebut kepada masyarakat dan pemerintah daerah. Hal ini dapat membahayakan, karena pengelolaan dan pemantauan lingkungannya tidak dapat diawasi.

RSIA Puri Agung belum melakukan pemantauan dan pelaporan secara rutin dikarenakan tidak mengetahui format pelaporan, Kantor Lingkungan Hidup Kota Magelang tidak memberitahukan pedoman pelaporan. Kendala lain adalah tidak ada karyawan khusus untuk pengelolaan lingkungan dan butuh anggaran besar dan lahan luas untuk membuat IPAL.

RSB Amandha belum melakukan pemantauan dan pelaporan secara rutin dikarenakan tidak mengetahui format pelaporan, Kantor Lingkungan Hidup Kota Magelang tidak memberitahukan pedoman pelaporan. Kendala lain adalah sumber daya manusia dan anggaran. Pemantauan kualitas air dengan parameter biologis rutin dilakukan karena dirasa penting, pemantauan kualitas udara dan kebisingan dirasa kurang perlu. 
Laboratorium Klinik Prodia belum melakukan pemantauan dan pelaporan secara rutin dikarenakan kurangnya sumber daya manusia, tingginya beban kerja dan anggaran yang besar.

Rumah Sakit Harapan belum dilakukan pemantauan dan pelaporan secara rutin dikarenakan sulit mengubah pola pikir agar memberi perhatian terhadap lingkungan, Rumah Sakit Harapan masih berorientasi pada keuntungan materi daripada mengelola lingkungan karena statusnya sebagai rumah sakit swasta, sosialisasi yang dilakukan Kantor Lingkungan Hidup Kota Magelang tahun 2011 lebih ditekankan pada pemrakarsa yang belum memiliki UKL-UPL daripada mengevaluasi yang sudah memiliki, beban kerja yang tinggi, tidak ada bagian dan SDM khusus untuk pengelolaan lingkungan.

RS Lestari Raharja sedang mengajukan proposal kepada Dinas Kesehatan Kota Magelang untuk pembangunan IPAL yang akan ditanam di bawah tanah. Hal ini dilakukan karena anggaran IPAL besar dan lahan yang ada sempit. SDM juga menjadi kendala dalam pengelolaan lingkungan karena RS Lestari Raharja tidak memiliki karyawan yang berlatar belakang pendidikan kesehatan lingkungan. Selama ini tidak melakukan pelaporan karena tidak pernah ada anjuran ataupun teguran dari Kantor Lingkungan Hidup Kota Magelang.

Berdasarkan Peraturan Pemerintah Nomor 27 Tahun 2012 tentang Izin Lingkungan pada Pasal 73 menyatakan bahwa "Dokumen lingkungan yang telah mendapat persetujuan sebelum berlakunya Peraturan Pemerintah ini, dinyatakan tetap berlaku dan dipersamakan sebagai Izin Lingkungan." Hal ini berati semua dokumen UKL-UPL yang dimiliki objek penelitian berlaku dan dipersamakan sebagai izin lingkungan. Oleh karena itu Pasal 53 mengenai kewajiban pemegang izin lingkungan diberlakukan. Pasal 53 ayat (1) menyatakan bahwa "Pemegang Izin Lingkungan berkewajiban:

a. menaati persyaratan dan kewajiban yang dimuat dalam Izin Lingkungan dan izin perlindungan dan pengelolaan lingkungan hidup;

b. membuat dan menyampaikan laporan pelaksanaanterhadap persyaratan dan kewajiban dalam Izin Lingkungan kepada Menteri, gubernur, atau bupati/walikota; dan

c. menyediakan dana penjaminan untuk pemulihan fungsi lingkungan hidup sesuai dengan peraturanperundang-undangan.

Pasal 53 ayat (2) menyatakan bahwa "Laporan sebagaimana dimaksud pada ayat (1) huruf b disampaikan secara berkala setiap 6 (enam) bulan."

Berdasarkan Pasal 53 tersebut diatas, objek penelitian wajib melaksanakan dan menaati persyaratan dan kewajiban yang dimuat dalam Izin Lingkungan serta membuat dan menyampaikan laporan pelaksanaan hal tersebut kepada Walikota Magelang. Tetapi pada kenyataannya, berdasarkan data yang didapat dari Kantor Lingkungan Hidup Kota Magelang bahwa hingga bulan Agustus 2012, pelaporan mengenai pelaksanaan pengelolaan dan pemantauan lingkungan oleh pemrakarsa di bidang kesehatan sebanyak 0\%, artinya tidak ada satupun pemrakarsa yang melaporkan pelaksanaan pengelolaan dan pemantauan lingkungan yang dilakukan kepada Kantor Lingkungan Hidup Kota Magelang, hal ini menunjukkan pemrakarsa telah melanggar aturan yang berlaku. Oleh karena itu, Pasal 71 dapat diberlakukan. Pasal 71 ayat (1) menyatakan bahwa "Pemegang Izin Lingkungan yang melanggar ketentuan sebagaimana dimaksud dalam Pasal 53 dikenakan sanksi administratif yang meliputi:

a. teguran tertulis;

b. paksaan pemerintah;

c. pembekuan Izin Lingkungan; atau

d. pencabutan Izin Lingkungan.

Sedangkan Pasal 71 ayat (2) menyatakan bahwa "Sanksi administratif sebagaimana dimaksud pada ayat (1) diterapkan oleh Menteri, gubernur, atau bupati/walikota sesuai dengan kewenangannya."

Sanksi administratif yang dinyatakan pada Pasal 71 tersebut didasarkan pada tingkat ketaatan pemegang Izin Lingkungan dalam hal ini adalah pemrakarsa di kelima objek penelitian terhadap pelaksanaan kewajiban yang tertuang di dalam Izin Lingkungan yang dimiliki dan juga didasarkan pada riwayat ketaatan pemegang Izin Lingkungan. Hal ini sesuai dengan apa yang tertuang di dalam Pasal 72 yang menyatakan bahwa "Penerapan sanksi administratif sebagaimana dimaksud dalam Pasal 71 ayat (2) didasarkan atas:

a. efektivitas dan efisiensi terhadap pelestarian fungsi lingkungan hidup;

b. tingkat atau berat ringannya jenis pelanggaran yang dilakukan oleh pemegang Izin Lingkungan;

c. tingkat ketaatan pemegang Izin Lingkungan terhadap pemenuhan perintah atau kewajiban yang ditentukan dalam izin lingkungan;

d. riwayat ketaatan pemegang Izin Lingkungan; dan/atau

e. tingkat pengaruh atau implikasi pelanggaran yang dilakukan oleh pemegang Izin Lingkungan pada lingkungan hidup."

\subsection{Pengawasan Kantor Lingkungan Hidup Kota Magelang}

Pengawasan yang dilakukan oleh Kantor Lingkungan Hidup Kota Magelang selama ini belum sesuai dengan yang diharapkan. Menurut Irwan Adhie Nugroho, Kepala Seksi Pencegahan Pencemaran Lingkungan, hal ini dikarenakan oleh keterbatasan sumber daya manusia yang dimiliki oleh Kantor Lingkungan Hidup Kota Magelang, baik dari segi kuantitas maupun 
kualitas, selain itu waktu yang ada juga menjadi kendala karena di luar pengawasan masih banyak kegiatan lain yang menjadi tugas dari Kantor Lingkungan Hidup Kota Magelang. Pembinaan terhadap usaha dan/atau kegiatan selama ini lebih memprioritaskan kuantitas daripada kualitas. Pembinaan lebih difokuskan pada usaha dan/atau kegiatan yang belum memiliki dokumen lingkungan hidup daripada mengevaluasi yang sudah memiliki. Menurut Machbub Yani Arfian, Kepala Kantor Lingkungan Hidup Kota Magelang, struktur kelembagaan berupa kantor juga memberi pengaruh terhadap pengawasan, struktur kelembagaan berupa kantor lebih bersifat teknis bukan koordinatif, sedangkan untuk mengelola lingkungan instansi lingkungan hidup tidak bisa berjalan sendiri, butuh koordinasi dengan instansi terkait lainnya.

\section{Kesimpulan}

Pemrakarsa di bidang kesehatan di Kota Magelang belum taat dalam pengelolaan dan pemantauan lingkungan, dikarenakan : 1) Belum menyadari bahwa lingkungan hidup adalah kepentingan publik yang tidak boleh dirusak. 2) SDM dan sarana kurang memadai. 3) Anggaran besar. Pengawasan yang dilakukan Kantor Lingkungan Hidup Kota Magelang bersifat reaktif.

\section{Ucapan Terimakasih}

Penulis menyampaikan terima kasih kepada Kepala Pusat Pembinaan Pendidikan dan Pelatihan PerencanaBadan Perencanaan Pembangunan Nasional (Pusbindiklatren-Bappenas) dan Pemerintah Kota Magelang atas beasiswa dan kesempatan belajar yang diberikan.

\section{Daftar Pustaka}

Abdul Kadir Sabaruddin, 2007, 'Amdal dan Kewenangan Bapedalda Dalam Menjaga Pelestarian Fungsi Lingkungan Hidup di Kota Balikpapan', Risalah Hukum Fakultas Hukum Unmul, Juli 2007, halaman 13-20, volume 3 No. 1, ISSN 021-969.X
Nusa Idaman Said, 2006, 'Pelaksanaan AMDAL, UKLUPL, serta IPLC di DKI', JAI, Volume 2 Nomor 2, Halaman 149-162, http://scholar.google.co.id/scholar?hl=id\&nu $\underline{m=50 \& q=p e l a k s a n a a n+A M D A L} \% 2 C+U K L+U P$ L+dan+IPLC+di+DKI+jakarta+Nusa+Idaman+ Said\&btnG=Telusuri\&as ylo=\&as vis $=0$, diakses 4 November 2011

Ross, W.A., Saunders, A.M. and Marshall, R., 2006, Common Sense in Environmental Impact Assessment: 'It Is Not As Common As It Should Be, Impact Assessment And Project Appraisal', volume 24, nomor 1, halaman 3-22, http://docserver.ingentaconnect.com/deliver/c onnect/beech/14615517/v24n1/s2.pdf?expire $\underline{\mathrm{s}=1322470635 \& \mathrm{id}=65931791 \& \text { titleid }=896 \& \text { acc }}$ $\underline{\text { name }=\text { Diponegoro+University\&checksum }=\mathrm{E} 3 \mathrm{E}}$ EDC68D5A1778F20B3BDECE5AC56BB, diakses 28 november 2011

Sukadji Sarbi, 2006, 'Strategi Pengembangan Kapasitas Pengelolaan Lingkungan Hidup di Era Otonomi Daerah Kabupaten Polmas Sulawesi Barat', Jurnal Bumi Lestari, Volume 6 No. 2, Agustus 2006, halaman 100-105

Undang-undang Republik Indonesia Nomor 32 Tahun 2009 tentang Perlindungan dan Pengelolaan Lingkungan Hidup

Peraturan Menteri Negara Lingkungan Hidup Nomor 13 Tahun 2010 tentang Upaya Pengelolaan Lingkungan dan Upaya Pemantauan Lingkungan Hidup dan Surat Pernyataan Kesanggupan Pengelolaan dan Pemantauan Lingkungan Hidup

Peraturan Menteri Negara Lingkungan Hidup No. 5 Tahun 2011 tentang Program Penilaian Peringkat Kinerja Perusahaan Dalam Pengelolaan Lingkungan Hidup. 